engagement for authors to receive feedback as well as a convenient way for APSA colleagues to share feedback or find opportunities for collaboration, all while eliminating high printing costs and travel risks for poster authors.

The packed APSA exhibit hall featured 75 organizations including political science publishers, news and media outlets, educational technology companies, research organizations, foundations, and nonprofit organizations. A robust variety of sponsored social events on the exhibit show floor also provided valuable opportunities for networking outside the sessions, including the Headshot Lounge, sponsored by Pearson, which allowed APSA attendees to have new professional photographs taken. As always, the APSA Lounge offered a comfortable space for where attendees could meet to discuss issues of mutual interest.

APSA would also like to express our deep appreciation to our corporate sponsors: Cambridge University Press, Routledge, the Agenda Game, Diplomacy Center Foundation, the Foreign Policy Association, Lynne Rienner Publishers, Nature Human Behavior, Oxford University Press, Pearson, Pi Sigma Alpha, The Quality of Government Institute, Varieties of Democracy, and West Acadmic.

We are very much looking forward to our next annual meeting in San Francisco, August 31-September 3, 2017. See you there! $\square$

\title{
APSA Awards
}

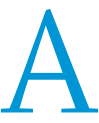

$\mathrm{t}$ the 2016 APSA Awards Ceremony, the association recognized an exceptional group of diverse individuals for their contributions to political science. This year, more than 20 distinguished award committees carefully considered a field of nearly 500 candidates, and the association is pleased to honor these outstanding scholars. The ceremony was held on Wednesday, August 31, at the Marriott Philadelphia Downtown. 2016 Annual
Meeting Program Chairs, Kimberly Morgan, The George Washington University, and Deborah Schildkraut, Tufts University recognized each award winner. Here are some photographs of the ceremony and awardees (video portions of the ceremony will be available on www.PoliticalScienceNow.com). A complete list of the awards is included in the Gazette section of this issue, and a listing of the Organized Section awards is provided later in this section.

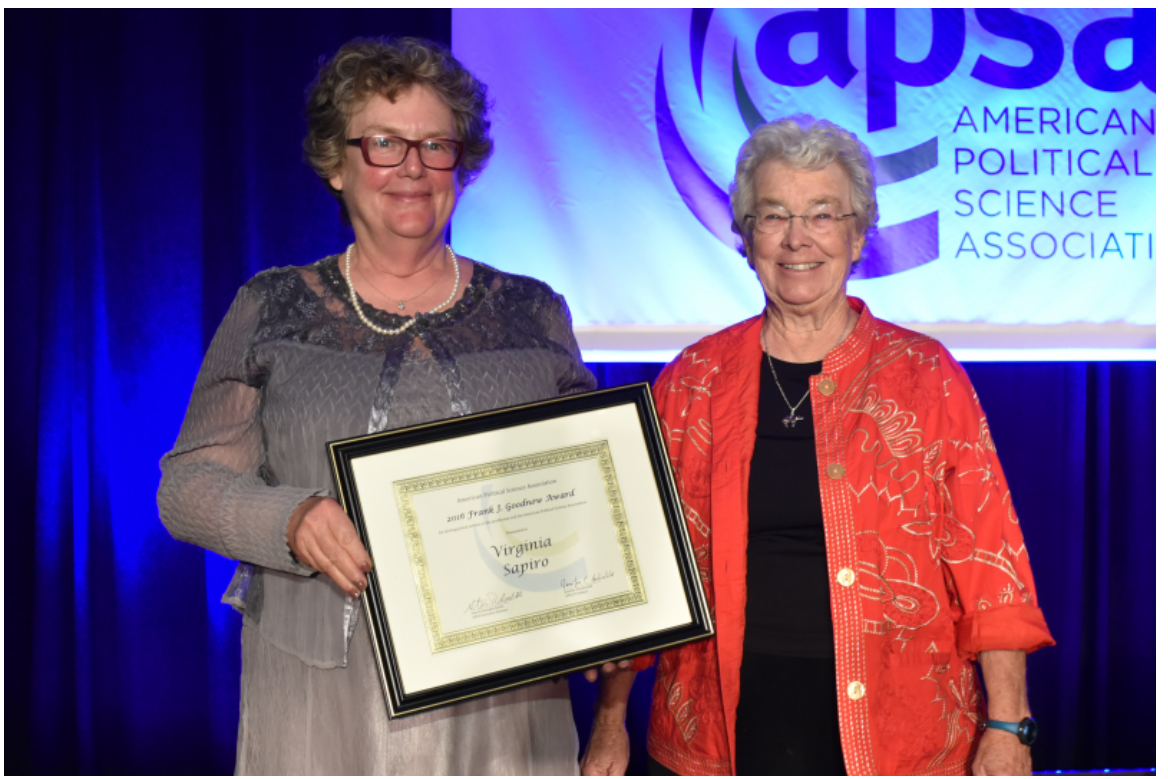

Left: Virginia Sapiro, Boston University, receives the Goodnow Award from Anne Schneider, Arizona State University. Sapiro's outstanding career opened an entire subfield in political science and created a path for women in the profession.

Below Left: Robert Huckfeldt, University of California, Davis, receives the Ithiel de Sola Pool Award from Deborah Schildkraut, Tufts University University. Huckfeldt's prolific contributions to political science have improved the profession's understanding of political behavior.

Below Right: Rosemary O'Leary, University of Kansas, receives the John Gaus Award from Kimberly Morgan, The George Washington University. O'Leary - a leader in the fields of environmental law and policy as well as public administration-has not only been a prolific researcher but also an extensive collaborator.
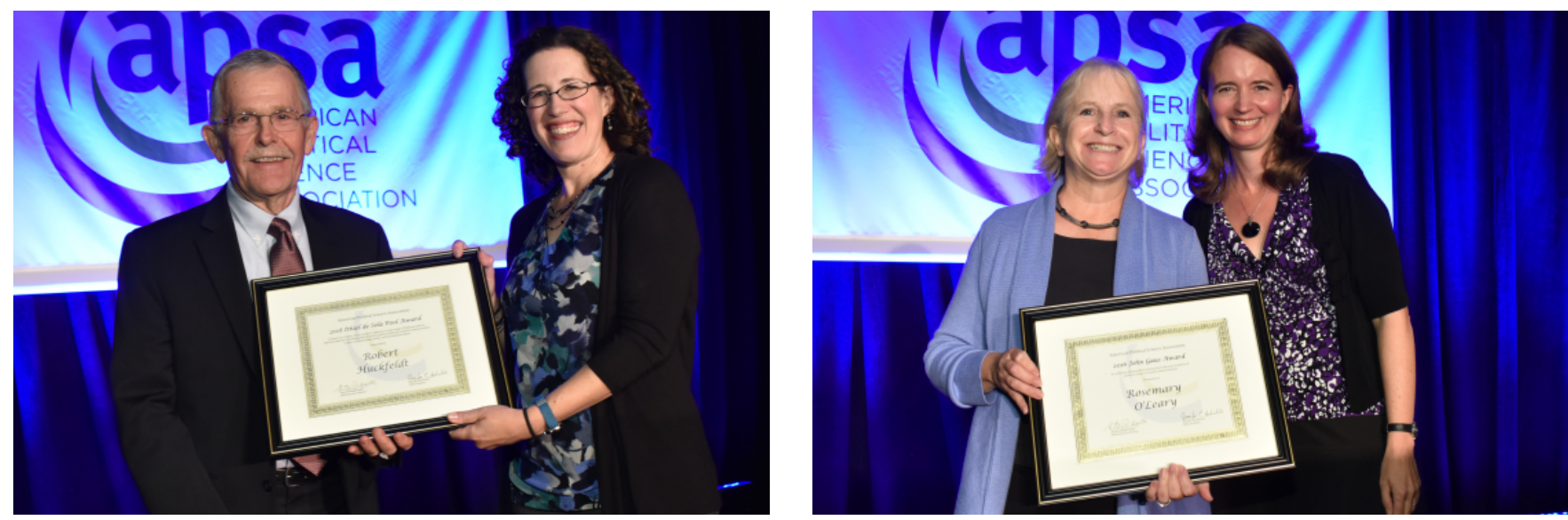


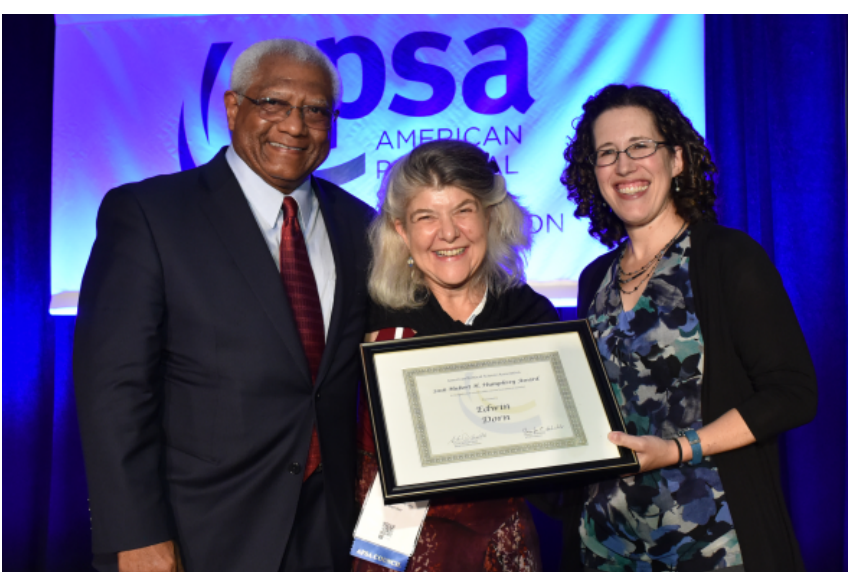

Edwin Dorn, University of Texas at Austin, (left) receives the Hubert $\mathrm{H}$. Humphrey Award for his work in multiple administrations. The award recognizes notable public service by a political scientist.

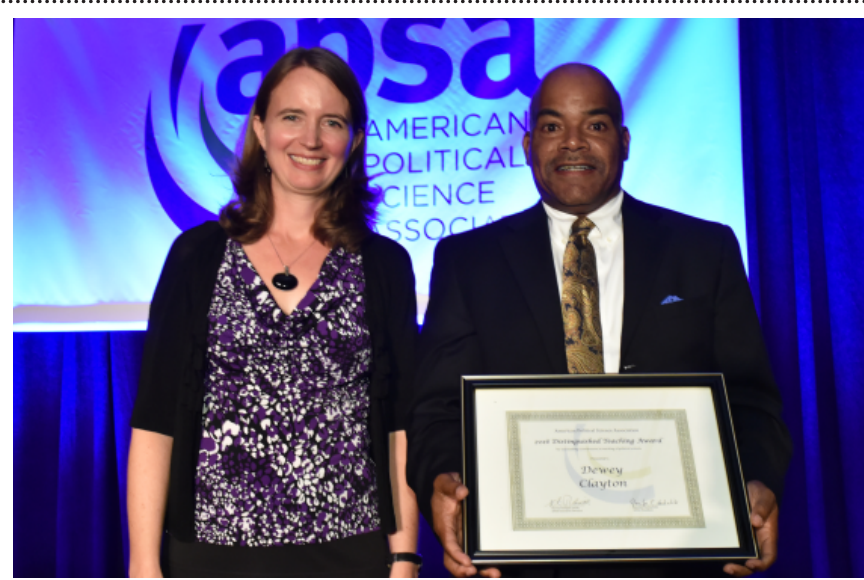

Dewey Clayton, University of Louisville, receives the Distinguished Teaching Award, which honors the outstanding contribution to undergraduate and graduate teaching of political science at two- and four-year institutions.
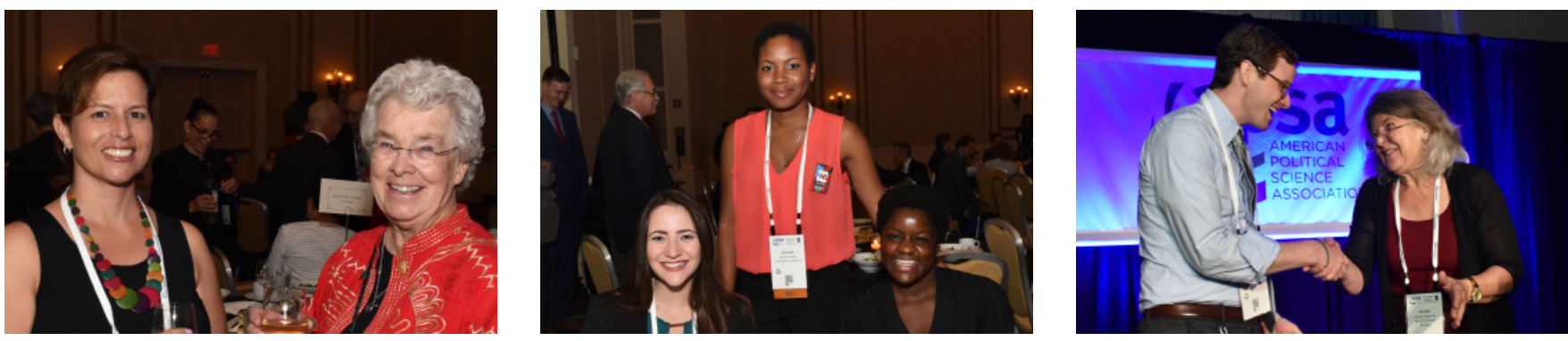

Guests enjoyed spending the evening to celebrate excellence in the profession. Left: Lina Newton chats with Anne Schneider, Arizona State University. Both served on award committees that spent hours considering many excellent candidates. Center: RBSI Scholars Heidi Obediente (L), Danielle Russell (C), and Jasmine Smith gather at the awards ceremony. Right: Jennifer Hochschild adds her word of congratulations to David Jones for his award.

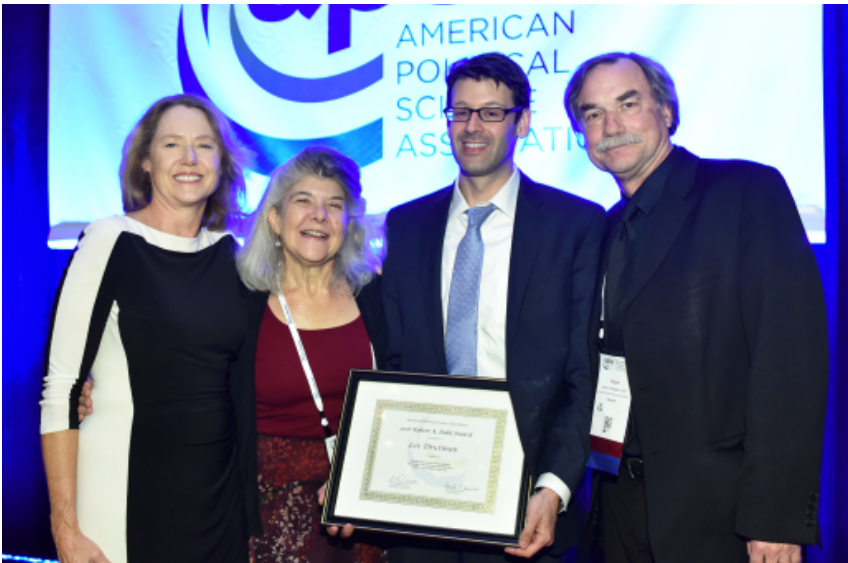

Lee Drutman, Senior Fellow, Political Reform Program, New America receives the inaugural Robert A. Dahl Award for his book The Business of America is Lobbying. He is joined by (left to right) Jane Thery, Organization of American States; Jennifer Hochschild, Harvard University; and Steven Rathgeb Smith, APSA executive director.

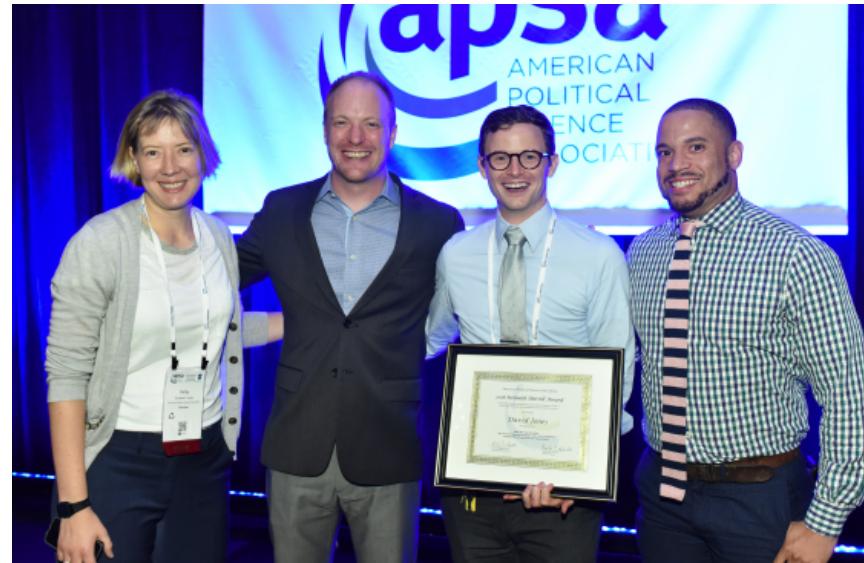

David Jones receives the Kenneth Sherrill Award for his dissertation "While Marriage Was Won: How Focused Litigation Campaigns Affect the Development and Priorities of Legal Advocacy Organizations." He is Joined by (left to right) Betsy Super, APSA; Patrick Egan, New York University; and Ravi Perry, Virginia Commonwealth University. 